\title{
Hydrogen Sulfide Is Increased in Oral Squamous Cell Carcinoma Compared to Adjacent Benign Oral Mucosae
}

\author{
ANDREW T. MERAM ${ }^{1}$, JIE CHEN ${ }^{2}$, STAVAN PATEL ${ }^{1}$, DONGSOO D. KIM ${ }^{1}$, BRETT SHIRLEY ${ }^{1}$, \\ PAUL COVELLO ${ }^{1}$, DOMENICO COPPOLA ${ }^{3}$, ERIC X. WEI $^{2}$, GHALI GHALI ${ }^{1}$, \\ CHRISTOPHER G. KEVIL ${ }^{2}$ and RODNEY E. SHACKELFORD ${ }^{2}$
}

\author{
${ }^{1}$ Head \& Neck Oncologic/Microvascular Reconstructive Surgery Department of Oral \& Maxillofacial/Head \& Neck \\ Surgery, Louisiana State University Health Sciences Center, Shreveport, LA, U.S.A.; \\ ${ }^{2}$ Department of Pathology and Translational Pathobiology Louisiana \\ State University Health Sciences Center, Shreveport, LA, U.S.A.; \\ ${ }^{3}$ Department of Anatomic Pathology, H. Lee Moffitt Cancer Center and Research Institute, Tampa, FL, U.S.A.
}

\begin{abstract}
Background/Aim: Hydrogen sulfide $\left(\mathrm{H}_{2} \mathrm{~S}\right)$ and the enzymes that synthesize it, cystathionine-b-synthase, cystathionine $\gamma$-lyase, and 3-mercaptopyruvate, are increased in different human malignancies. Due to its short half-life, $\mathrm{H}_{2} \mathrm{~S}$ concentrations have not been directly measured in a human malignancy. Here we directly measured in vivo $\mathrm{H}_{2} \mathrm{~S}$ levels within oral squamous cell carcinoma (OSCC). Patients and Methods: Punch biopsies of OSCC and benign mucosae from 15 patients were analyzed by HPLC, western blotting, and tissue microarray analyses. Results: $\mathrm{H}_{2} \mathrm{~S}$ concentrations were significantly higher in OSCC compared to adjacent benign oral mucosae. Western blot and tissue microarray studies revealed significantly increased cystathionine-b-synthase, cystathionine $\gamma$-lyase, and 3-mercaptopyruvate, phopho-Stat3, mitoNEET, hTERT, and MAPK protein levels in OSCC. Conclusion: $\mathrm{H}_{2} \mathrm{~S}$ concentrations and the enzymes that synthesize it are significantly increased in OSCC. Here, for the first time $\mathrm{H}_{2} \mathrm{~S}$ concentrations within a living human malignancy were measured and compared to adjacent counterpart benign tissue.
\end{abstract}

Worldwide head and neck cancers are the sixth most common cancer type and are frequently epithelial aerodigestive tract malignancies (1). Approximately $75 \%$ are

This article is freely accessible online.

Correspondence to: Rodney E. Shackelford, Department of Pathology and Translational Pathobiology, Louisiana State University Health Sciences Center, Shreveport, LA, U.S.A. Tel: +1 3186751228, e-mail: rshack@1suhsc.edu

Key Words: Hydrogen sulfide, H2S, mitoNEET, cystathionine- $\beta$ synthase, cystathionine $\gamma$-lyase, 3-mercaptopyruvate. oral cancers, with $90 \%$ of these being oral squamous cell carcinomas (OSCC, 1-3). The remaining 10\% consist of salivary gland tumors, lymphomas, and rare sarcomas (3). The five- and ten-year survival rates for these cancers are $59 \%$ and $48 \%$, respectively, with these survival rates not having significantly improved for thirty years (1-3). The tongue is commonly effected, particularly the lateral-ventral surface, with other common locations being the oropharynx, floor of the mouth, and soft palate (4).

The risk factors for OSCC include tobacco, alcohol, areca nut, ultraviolet radiation exposure, and immunosuppression (5). OSCC typically arises from precursor lesions, such as submucosal fibrosis, erythro- and leukoplakias, actinic cheilosis, and oral lichen planus $(2,4,5)$. Compared to benign oral squamous epithelium, OSCC precursors accumulate complex molecular changes that evolve over time as the lesions progress from precursor lesions, to oral OSCC, and eventually to metastatic disease (5-8). These changes include regional chromosomal gains and losses, tumor suppressor gene loss/inactivation, activation of cell growth promoting signal transduction pathways, and complex alterations in miRNA expression and epigenetic gene regulatory patterns (5-7). One study found 2,891 genes differentially expressed in OSCC compared to benign oral squamous epithelium, demonstrating the high complexity of OSCC malignant transformation (8). Altered signal transduction pathways important in OSCC growth include the changes/increases in the cyclin D1, epidermal growth factor/transforming growth factor- $\alpha$, vascular endothelial growth factor, extracellular-signal regulated kinase, and AKT kinase-initiated pathways (5).

Hydrogen sulfide $\left(\mathrm{H}_{2} \mathrm{~S}\right)$ is a recently discovered gasotransmitter that exerts extensive regulatory effects in health and disease (9). Three enzymes synthesize $\mathrm{H}_{2} \mathrm{~S}$ : 
cystathionine- $\beta$-synthase (CBS), cystathionine $\gamma$-lyase (CSE), and 3-mercaptopyruvate (3-MST, 9, 10). Intracellular $\mathrm{H}_{2} \mathrm{~S}$ concentrations, and one or more of the $\mathrm{H}_{2} \mathrm{~S}$-synthesizing enzymes, show increased expression in cells derived from several malignant human tumors, including melanoma, and colon, breast, bladder, and ovarian carcinomas, when compared to adjacent non-cancerous tissue or nontransformed cells (11-16). Increased intracellular CBS protein expression stimulates tumor xenograft growth, angiogenesis, and peritumoral vascular tone, indicating that $\mathrm{H}_{2} \mathrm{~S}$ promotes tumor growth (11-16). $\mathrm{H}_{2} \mathrm{~S}$ concentrations, and CBS, CSE, and 3-MST protein expressions are also often increased at higher tumor grades and stages (12-16).

The half-life of $\mathrm{H}_{2} \mathrm{~S}$ is short, with one study done under aerobic conditions revealing $\mathrm{H}_{2} \mathrm{~S}$ half-lives of 2.0, 2.8, and $10.0 \mathrm{~min}$ in murine hepatic, renal, and brain homogenates, respectively (17). For this reason, increased tumor $\mathrm{H}_{2} \mathrm{~S}$ levels have been inferred from studies correlating the effects of $\mathrm{H}_{2} \mathrm{~S}$ donors/inhibitors and/or increases or decreases in CBS, CSE, and 3-MST enzyme levels with parameters such as tumor growth and invasion, clinical stage, tumor grade, and angiogenesis (11-16). One study showed that buffered bladder tumor homogenates provided with exogenous L-cysteine and phosphatepyridoxine aldehyde produced nearly four times more $\mathrm{H}_{2} \mathrm{~S}$ than comparable benign bladder tissue homogenates (15).

Exogenous $\mathrm{H}_{2} \mathrm{~S}$ increases the proliferation and cell cycle progression of human OSCC cell lines via activation of the COX2/AKT/ERK1/2 axis $(18,19)$. Additionally, compared to benign oral squamous epithelium, CBS protein levels are increased in OSCC and with higher expression seen at higher tumor grades (14). This data suggests that $\mathrm{H}_{2} \mathrm{~S}$ and the enzymatic pathways involved in its synthesis are increased in OSCC. Since OSCC and adjacent benign oral mucosae could easily and quickly be biopsied by punch biopsy technique and preserved in liquid $\mathrm{N}_{2}$ for later $\mathrm{H}_{2} \mathrm{~S}$ analysis, we performed these studies to directly measure OSCC $\mathrm{H}_{2} \mathrm{~S}$ concentrations and compare these measurements to adjacent benign oral mucosae. Additionally, tissue microarray was used to examine CSE and 3-MST levels in OSCC and western blotting to examine CBS, CSE, 3-MST, nicotinamide phosphoribosyltransferase (Nampt), mitoNEET, phospho-Stat3, hTERT, mitogen-activated protein kinase (MAPK), sulfide: quinone oxidoreductase (SQOR) and ataxia-telangiectasia mutated (ATM) protein levels in OSCC and adjacent benign oral mucosae.

\section{Materials and Methods}

Materials. Monobromobimane (MBB), Tris (2-carboxyethyl) phosphine hydrochloride (TCEP), sulfosalicylic acid (SSA), 1fluoro-2,4-dinitrobenzene (DNFB), diethylenetriaminepentaacetic acid (DTPA), sulfosalicylic acid (SSA), and $N$-ethylmaleimide (NEM) were purchased from Sigma (St. Louis, MO, USA). Polyvinylidene difluoride membranes were the source of the western blot membrane (Bio-Rad, Hercules, CA, USA, catalog number 170-4270). Antibodies used were anti-CBS (Santa Cruz Biotechnology, Santa Cruz, CA, USA, catalog number sc-67154), anti-CSE (Santa Cruz Biotechnology, catalog number sc-101924), anti-3-MST (Santa Cruz Biotechnology, catalog number sc-135993), anti-Visfatin (Nampt, Bethyl Laboratories, Montgomery TX, catalog number A300-779A), anti-phospho-Stat3 (ser727, Cell Signaling, Danvers, MA, USA, catalog number 9134S), anti-Stat3 (Cell Signaling, catalog number 12640S), anti-mitoNEET (Proteintech, Danvers, MA, USA, catalog number 16006-1-AP), anti-hTERT, (Millipore, Burlington, MA, USA, catalog number MABD55), antimitogen-activated protein kinase (MAPK, Cell Signaling, catalog number 4370), anti-SQOR (Boster Biological Technology, Pleasanton, CA, USA, catalog number A11155X), and anti-ATM (abcam, Cambridge, MA, catalog number ab199726). Secondary antibodies were goat anti-rabbit IgG (abcam, catalog numbers ab6721 and ab2040) and goat anti-mouse IgG (abcam catalog number ab205719), and goat anti-mouse IgG (Santa Cruz Biotechnology, catalog number sc358920).

Tissue Microarray (TMA). Upon Institutional Review Board (IRB) approval by LSU Health Shreveport, two TMAs catalog number OR208 were purchased from US Biomax, Inc. (Rockville, MD, USA). Two TMAs were purchased, so that they could be interrogated with both anti-CSE and anti-3-MST antibodies. Together the TMAs contained 28 benign oral cavity squamous epithelial samples and 186 oral SCC samples: 152 OSSC grade I, 22 OSSC grade II, and six OSCC grade III tumor samples. All tissue samples in the TMAs were in $1.0 \mathrm{~mm}$ diameter.

CSE and 3-MST immunohistochemistry (IHC). The concentration of primary CSE and 3-MST antibodies were optimized to normal kidney as control tissue. The staining of the TMAs was performed in the Tissue Core Histology Lab Facility at the Moffitt Cancer Center. The microarray slides were stained using a Ventana Discovery XT automated system (Ventana Medical Systems, Tucson, AZ, USA) as per the manufacturer's protocol with proprietary reagents. Briefly, the slides were deparaffinized on the automated system with EZ Prep solution (\#950-100; Ventana Medical Systems). The heat-induced antigen retrieval method was used in Cell Conditioning 1 (\#950-124; Ventana Medical Systems). Mouse monoclonal antibody to human CSE (abcam, catalog number ab54573), was used at a 1:1,000 concentration in Dako antibody diluent (Dako, Carpentaria, CA, USA, catalog number S0809) and incubated for $60 \mathrm{~min}$. The Santa Cruz mouse monoclonal antibody to human 3-MST (Santa Cruz Biotechnology, catalog number sc135993), was used under the same conditions. The Ventana antimouse secondary antibodies were used for $16 \mathrm{~min}$. The detection system used was the Ventana OmniMap kit. Slides were then dehydrated and cover-slipped as per standard laboratory protocol.

Evaluation of CSE and 3-MST staining. Relative CSE and 3-MST protein expression was determined as immunostain intensity scored on a zero to three scale as follows: no staining as zero, light staining as one, moderate staining as two, and heavy staining as three. The percentage of cells stained was measured, with no detectable staining as zero, $1-33 \%$ as one, $34-66 \%$ as two, and $67-100 \%$ as three. The final IHC score was the product of the percentage of cells stained, multiplied by the intensity score, allowing for a minimal score of zero and a maximal score of nine. Nuclear and cytoplasmic Nampt and CBS staining were seen in all tissue samples examined, 
although at low levels in benign oral epithelia. We therefore measured and quantified CSE and 3-MST staining in the nuclear and cytoplasmic compartments.

TMA Statistical analysis. The standard error of the mean (SEM) IHC score was calculated by taking the mean of each data set, subtracting the mean from each number in the set and squaring the result, then calculating the mean of the squared differences, and taking the square root of this number to find the standard deviation. The standard deviation was divided by the square root of the number of tissue samples in the sample set to find the SEM. This statistical analysis was the same as performed on a previous TMA study of CBS levels in OSCC (14).

Patients. After obtaining IRB approval, patients were selected based on the presence of a T2 or greater OSCC. From February 2017 to December 2017, 116 patients presented to one of the oncology clinics within the department of Oral and Maxillofacial Surgery at our institution for evaluation of an oral cavity lesion. Either the lesions had been previously biopsied by an outside physician and were likely OSCC, or they were biopsied by one of our physicians and returned as OSCC. If surgical resection was chosen as the primary treatment modality, patients with $\mathrm{T} 2$ or greater OSCCs were asked if they would approve of being enrolled in our study. If they opted to participate, IRB-approved informed consent was obtained. After inclusion criteria had been met, twenty patients were enrolled in the study. They ranged in age from 47 to 83 years, with various oral cavity tumor locations (Table I). On the morning of each surgery, the tumor was identified and a $1.5 \mathrm{~cm}$ margin was marked circumferentially around the tumor in the standard oncologic fashion. Once the surgical margin was demarcated, three separate $3.0 \mathrm{~mm}$ punch biopsies were obtained from the periphery of the resection margin in what was deemed to be benign tissue, as well as three separate $3 \mathrm{~mm}$ punch biopsies from the center of the malignancy. A separate punch biopsy was used for the benign specimens as well as the malignant specimens to prevent cross-contamination. Any excess blood on the specimens was blotted away with a surgical lap sponge to prevent any blood contamination. These specimens were individually placed in Eppendorf tubes labeled as "benign" numbers one to three and "malignant" numbers one to three. They were immediately sealed, placed into a bath of liquid nitrogen, and passed on to the pathologist for further testing. Less than twenty sec elapsed between obtaining each specimen and final placement in the liquid nitrogen bath. All tissue samples were examined and staged by experienced, board-certified pathologists, to confirm that the tissues used were either benign oral mucosae or OSCC. Of the twenty samples, three were lost due to excess necrosis or being too bloody, and two were non-OSCC tumors; thus, leaving fifteen OSCCs and benign mucosal-paired samples analyzed (Table I).

Western blots. Whole cell lysates where prepared from the liquid $\mathrm{N}_{2}$ frozen surgical biopsies. Following weighing and quick thawing, the tissue samples were lysed in chilled RIPA buffer $(20 \mathrm{mM}$ Tris- $\mathrm{HCl}$, $150 \mathrm{mM} \mathrm{NaCl}, 1 \%$ Triton-X100, $0.1 \%$ SDS, 1 mM EDTA, $1 \%$ sodium deoxycholate, $1 \mathrm{mM}$ PMSF, $5 \mu \mathrm{g} / \mathrm{ml}$ Leupeptin) at $1 \mathrm{mg}$ tissue $/ 10 \mu \mathrm{l}$ RIPA buffer. The tissue was next homogenized by tekmar tissumizer, centrifuged at $12,000 \mathrm{~g}$ at $4^{\circ} \mathrm{C}$ for $10 \mathrm{~min}$, and the supernatant transferred to a new tube. The protein concentration was measured by Bio-rad DC protein assay. Ten- $20 \mu \mathrm{g}$ protein supernatant extract was mixed with $2 \mathrm{X}$ SDS loading buffer according to the protein
Table I. Profiles of the fifteen patients enrolled in this study.

\begin{tabular}{|c|c|c|c|c|}
\hline Age & $\begin{array}{l}\text { Tumor } \\
\text { size }\end{array}$ & $\begin{array}{l}\text { Tumor } \\
\text { type }\end{array}$ & $\begin{array}{l}\text { Tumor } \\
\text { grade }\end{array}$ & $\begin{array}{l}\text { Tumor } \\
\text { location }\end{array}$ \\
\hline 62 & $\mathrm{~T} 2$ & OSCC & II & Right tongue \\
\hline 49 & T4a & OSCC & II & Right mandible \\
\hline 54 & $\mathrm{~T} 4 \mathrm{a}$ & OSCC & II & Mandible/Floor of mouth \\
\hline 69 & $\mathrm{~T} 2$ & OSCC & II & Floor of mouth \\
\hline 51 & $\mathrm{~T} 2$ & OSCC & I & Left retromolar trigone \\
\hline 56 & $\mathrm{~T} 2$ & OSCC & I-II & Left tongue \\
\hline 73 & $\mathrm{~T} 4 \mathrm{a}$ & OSCC & II & Anterior Mandible \\
\hline 77 & $\mathrm{~T} 2$ & OSCC & III & Left floor of mouth \\
\hline 55 & $\mathrm{~T} 2$ & OSCC & II & Right mandibular alveolar ridge \\
\hline 47 & $\mathrm{~T} 3$ & OSCC & II & Left tongue \\
\hline 77 & $\mathrm{~T} 4 \mathrm{a}$ & OSCC & II & Left mandible \\
\hline 49 & $\mathrm{~T} 2$ & OSCC & II & Left tongue \\
\hline 55 & $\mathrm{~T} 3$ & OSCC & II & Right tongue \\
\hline 52 & $\mathrm{~T} 2$ & OSCC & II & Left buccal mucosa \\
\hline 83 & $\mathrm{~T} 4$ & OSCC & II & Right mandible \\
\hline
\end{tabular}

concentration. The protein sample was then loaded onto an SDS gel or placed at $-20^{\circ} \mathrm{C}$ for storage. Lysates separated by SDS-PAGE were transferred to polyvinylidene difluoride membranes, and membranes were blocked in 5\% nonfat dry milk in $1 \mathrm{X}$ PBS before the addition of the primary antibodies. GAPDH was used as a western blot loading control, except for the phospho-Stat3 ser727 blots, where an anti-Stat3 antibody was employed. Some of the antibodies to specific proteins were added to the study at later time points than were CBS, CSE, 3MST, and Nampt, and hence there were fewer OSCC/benign mucosal pairs interrogated.

$\mathrm{H}_{2} \mathrm{~S}$ measurements. Bioavailable $\mathrm{H}_{2} \mathrm{~S}$ levels were measured as previously reported $(20,21)$. Levels of free sulfide in the OSCC/benign mucosal-paired samples were measured by high performance liquid chromatography (HPLC) after derivatization with excess MBB as stable products sulfide-dibimane (SDB). Briefly, oral tissue samples were homogenized in Tris $\cdot \mathrm{HCl}$ buffer $[100 \mathrm{mM}$ Tris $\cdot \mathrm{HCl}(\mathrm{pH} 9.5)$ and $0.1 \mathrm{mM}$ diethylenetriaminepentaacetic acid (DTPA)]. Cell lysates were derivatized with MBB and then measured by Shimadzu Prominence 20A equipment with RF-10AXL (excitation wavelength: $390 \mathrm{~mm}$ and emission wavelength: $475 \mathrm{~mm}$ ) and an Eclipse XDB-C18 column $(4.6 \times 250 \mathrm{~mm}, 5 \mu \mathrm{m})$. Typical retention times of SDB were around $16.5 \mathrm{~min}$. Free $\mathrm{H}_{2} \mathrm{~S}$ levels were calculated according to standard $\operatorname{SDB}(20,21)$.

$\mathrm{H}_{2} \mathrm{~S}$ and western blot statistical analysis. Data for the western blots and $\mathrm{H}_{2} \mathrm{~S}$ measurements were normalized with image $\mathrm{J}$ densitometry software and significance was calculated by using prism software version 5.02 (GraphPad Inc., San Diego, CA, USA).

\section{Results}

Tissue microarrays. Following processing, four benign oral cavity squamous epithelial samples were lost in each TMA. The remaining tissue samples were not lost. As shown in Figure 1 and Table II, both CSE and 3-MST were increased 
Table II. Relative CSE and 3-MST staining in the two tissue microarrays comparing benign squamous epithelium, and OSCC, grades I-III.

\begin{tabular}{lcccccc}
\hline Antibody & CSE number & 3-MST number & CSE IHC score & 3-MST IHC score & CSE SEM & 3-MST SEM \\
\hline Benign squamous epithelium & 24 & 24 & 0.42 & 0.79 & 0.27 \\
SCC grade I & 152 & 152 & 0.71 & 1.41 & 0.40 \\
SCC grade II & 22 & 22 & 2.13 & 2.68 & 0.20 & 0.19 \\
SCC grade III & 6 & 6 & 3.33 & 4.00 & 0.61 & 0.18 \\
\hline
\end{tabular}

IHC: Averaged immunohistochemical score; SEM: standard error of the mean.

in OSCC compared to benign oral epithelia by TMA analysis. CSE and 3-MST expression increased with higher OSCC tumor grades, with CSE minimally expressed in benign squamous epithelia and increased in OSCC (Table II). This data, combined with a previous study, demonstrates that CBS, CSE, and 3-MST show higher protein expression in OSCC compared to benign oral squamous epithelia, with CBS more highly induced as measured by previous TMA analysis (14).

Western blotting. TMA analyses, while useful, can lack robustness and controls (22). To confirm and extend the TMA results, western blot analyses were performed on the fifteen surgical OSCC/benign mucosal samples (Table I). Western blotting was performed for CBS (15 patients), CSE (15 patients), 3-MST (15 patients), Nampt (15 patients), phosphoStat3 (10 patients), mitoNEET (14 patients), MARPK (10 patients), hTERT (9 patients), SQOR (10 patients), and ATM (11 patients, Table I). As shown in Figure $2 \mathrm{~A}$ and $\mathrm{D}$ and $2 \mathrm{~F}-2 \mathrm{H}$, CBS, CSE, 3-MST, Nampt mitoNEET, MARPK, and hTERT protein expression were increased in OSCC compared to benign oral mucosae. For Figure 2E, Stat 3 ser 727 phosphorylation was measured and was increased in the OSCC samples compared to benign oral mucosae. The significance value for these eight benign/OSCC comparisons was $p<0.001$. Mito NEET showed both the highest expression increases and the most reliable increases in OSCC compared to benign oral epithelium (Figure 2F, Table III). The SQOR and ATM proteins (Figures 2I and J), were not induced and the $p$-values for these western blots were not significant. The proteins examined, the number of cases, and their statistical significances in OCSS cases compared to counterpart benign tissue are shown in Table III.

Benign oral mucosal and OSCC $\mathrm{H}_{2} \mathrm{~S}$ measurements. When fifteen benign tissue/OSCC samples were compared, free $\mathrm{H}_{2} \mathrm{~S}$ was significantly increased in the OCSS compared to benign oral muscae (Figure 3).

\section{Discussion}

Previously TMA analysis revealed that CBS is increased in OSCC compared to benign oral squamous epithelium (14). In this study, a similar microarray analysis was used to establish that CSE and 3-MST are also increased in OSCC compared to benign oral epithelium (Table II, Figure 1). Since TMA analyses can lack adequate controls and can show low assay robustness, western blotting was used on our OCSS/benign oral mucosae pairs to look for changes in ten proteins (22). Each of these proteins was examined for specific reasons; 1) to examine the levels of the $\mathrm{H}_{2} \mathrm{~S}$-synthesizing enzymes (CBS, CSE, and 3-MST), 2) to identify new proteins increased in OCSS which may be related to $\mathrm{H}_{2} \mathrm{~S}$ metabolism (mitoNEET, phospho-Stat3, and SQOR), and 3) validify our results by examining proteins previously found to be either increased or not increased in OSCC (Nampt, MARPK, hTERT, and ATM). Due to the very short half-life of $\mathrm{H}_{2} \mathrm{~S}$, a time-consuming microdissection of the benign punch biopsy to include only benign squamous epithelium was not possible, hence here the term "benign oral mucosae" was use for these samples (17).

To initiate these studies CBS, CSE, and 3-MST protein expression were analyzed in the $15 \mathrm{OCSS} /$ benign tissue sample pairs. As shown in Figure $2 \mathrm{~A}$ and $\mathrm{C}$ all three enzymes were increased roughly 2.7 -fold in OSCC compared to adjacent benign tissue. Each enzyme was consistently increased in OSCC compared to benign tissue pair for all 15 pairs analyzed (Table III). Nampt levels were next examined as it is commonly increased in malignant tumors $(23,24)$. Nampt is regulated by CBS and CSE, with inhibition of either enzyme suppressing Nampt expression and increased cellular $\mathrm{H}_{2} \mathrm{~S}$ increasing Nampt expression $(23,24)$. Like the three $\mathrm{H}_{2} \mathrm{~S}$-synthesizing enzymes, Nampt was reliably increased on average 2.5-fold in every tumor-benign tissue sample comparison (Figure 2D, Table III). Our finding that Nampt is co-induced with CBS and CSE in OSCC lends some support to this circuit playing a role in OSCC (23).

Phospho-Stat3 ser727 plays an important role in oncogenic transformation, the regulation of Stat 3 activity, and is highly expressed in cervical squamous cell carcinoma (25-28). Stat3 phosphorylation is also increased following $\mathrm{H}_{2} \mathrm{~S}$ exposure, promotes cell survival and cyclin D1 expression, and increases CSE expression in breast cancer (29-31). Therefore, its expression in OSCC was examined as it is likely $\mathrm{H}_{2} \mathrm{~S}$ regulated and in turn may regulate CSE. As 

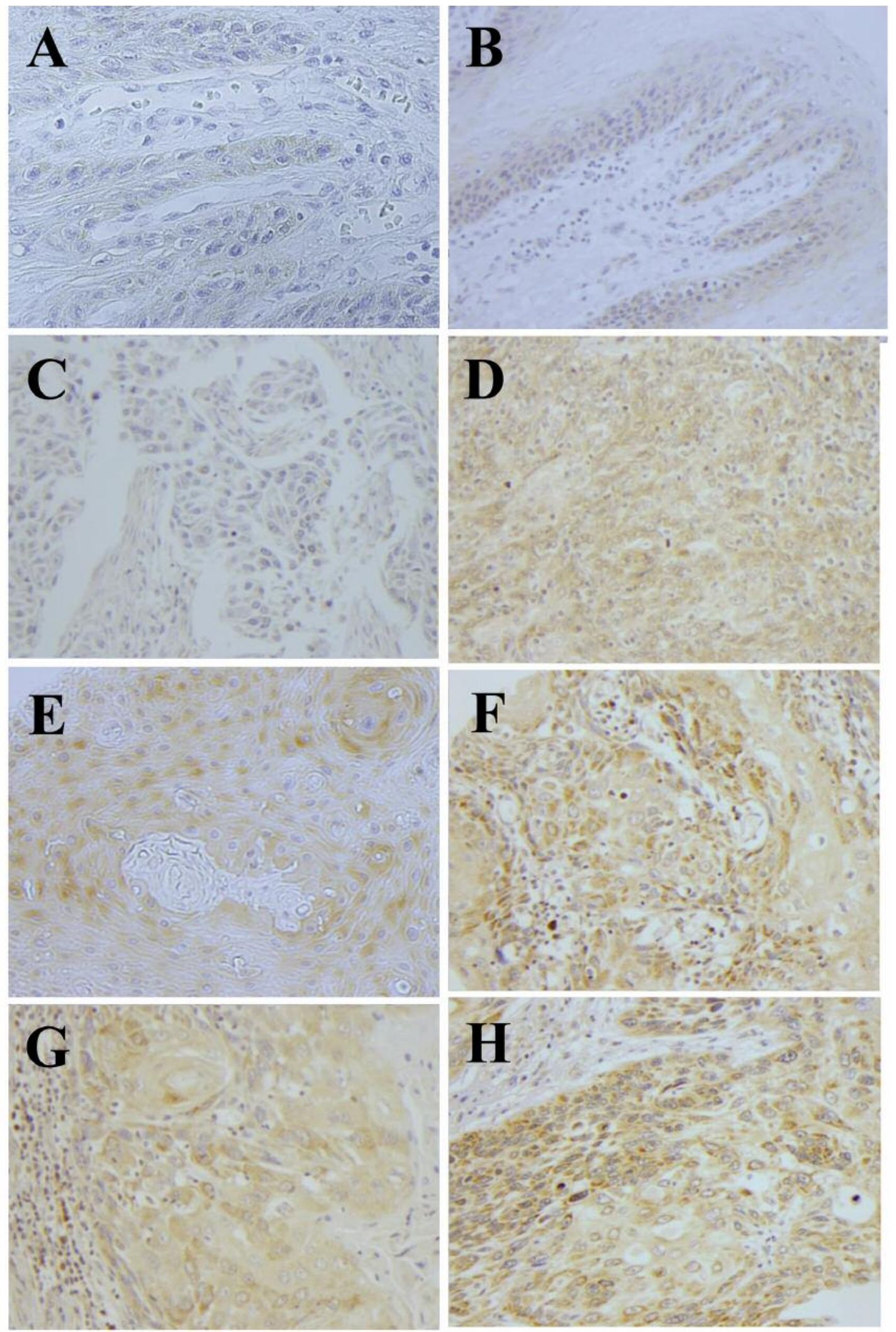

Figure 1. Representative immunostaining of benign oral squamous mucosae with CSE and 3-MST (A) and (B), respectively. Grade I (C and D), grade II ( $E$ and $F)$, and grade III ( $G$ and $H)$ OSCC were also stained for CSE and 3-MST, respectively. High-power views ( $\times 400)$. 

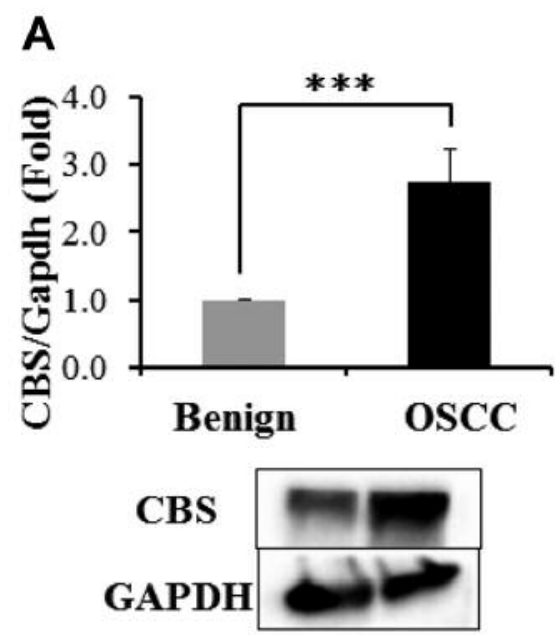

C
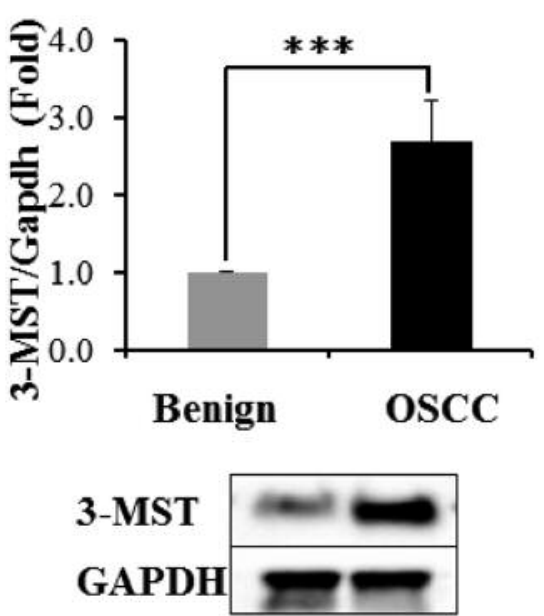

E

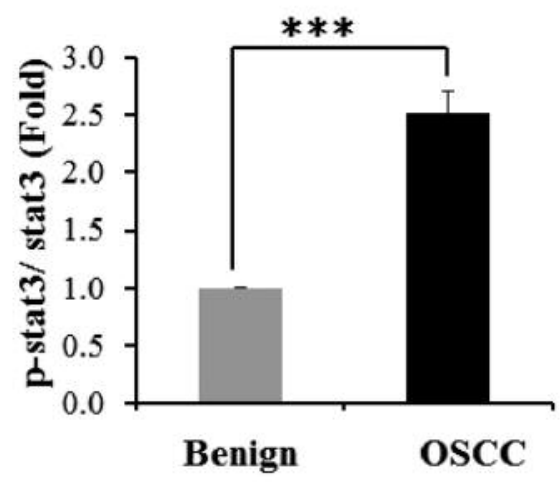

phospho-stat3

Total stat3
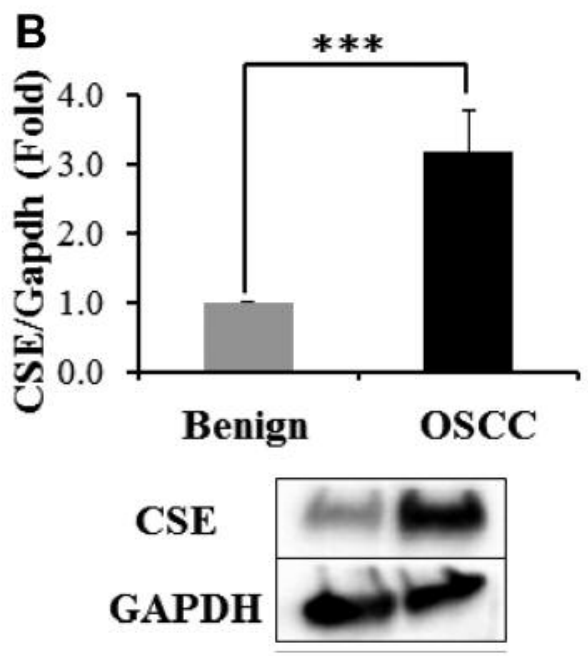

D

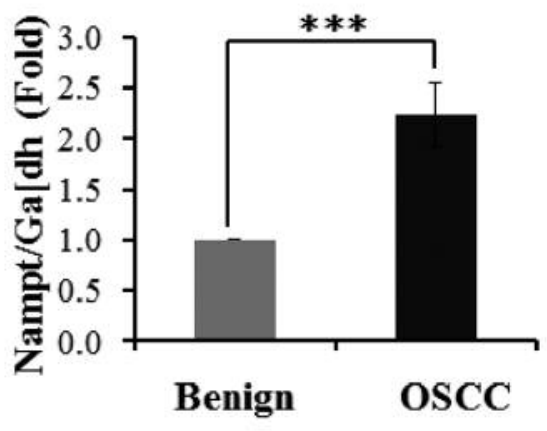

Nampt

GAPDH

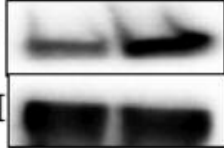

F
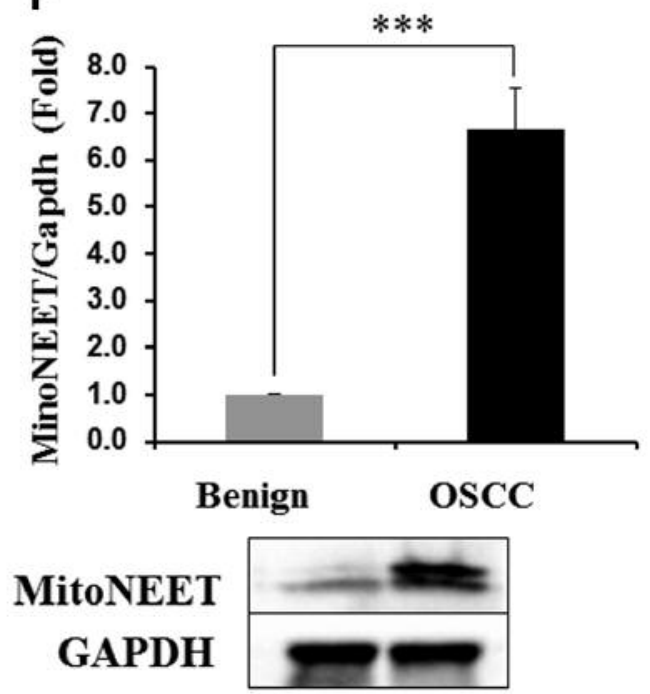

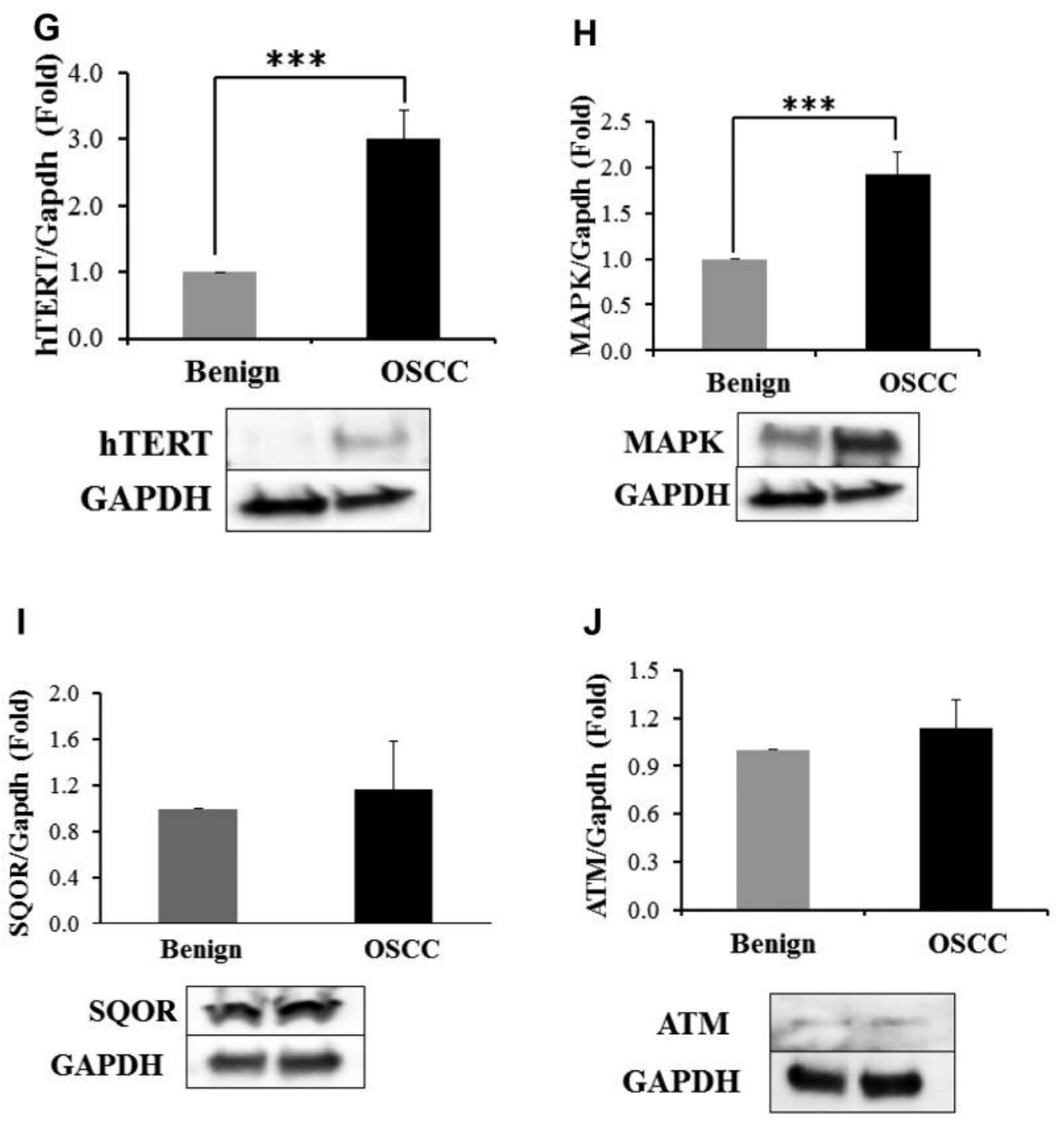

Figure 2. Western blot analyses of benign oral mucosae and OSCC for the CBS (A), CSE (B), 3-MST (C), Nampt (D), mitoNEET (E), phospho-Stat3 $(F), h T E R T(G), \operatorname{MAPK}(H), S Q O R(I)$ and ATM $(J)$ proteins. $* * * p<0.001$. SQOR and ATM (2I and $2 J)$ did not have statistically significant differences between benign oral epithelium and OSCC.

shown in Figure 2E, phospho-Stat3 ser727 was increased in OSCC compared to benign oral mucosae about 3.4-fold. To our knowledge, this is the first time this Stat3 phosphorylation has been observed in OSCC. We are currently examining its role in CSE regulation in OSCC.

MitoNEET is an outer mitochondrial iron-sulfur protein that shows increased expression in several human malignancies $(32,33)$. High tumor mitoNEET expression suppresses apoptosis, autophagy, and lowers intramitochondrial iron concentrations, likely allowing tumors cells to tolerate higher reactive oxygen species, while avoiding ferroptosis (33). The oxidation state of mitoNEET is regulated by glutathione reductase, a cellular redox regulator enzyme that catalyses the conversion of glutathione disulfide to glutathione, an enzymatic reaction requiring nicotinamide adenine dinucleotide phosphate (NADPH) as a substrate $(33,34)$. Since CBS, CSE, 3-MST, and glutathione reductase are highly expressed in OSCC and $\mathrm{H}_{2} \mathrm{~S}$ is a powerful activator of glucose-6-phosphate dehydrogenase, which leads to increased pentose phosphate shunt activation and subsequent increased intracellular NADPH levels, we hypothesized that mitoNEET would be increased in OSCC $(35,36)$. As shown in Figure $2 \mathrm{~F}$ and Table III, mitoNEET is strongly and significantly increased in OSCC compared to 


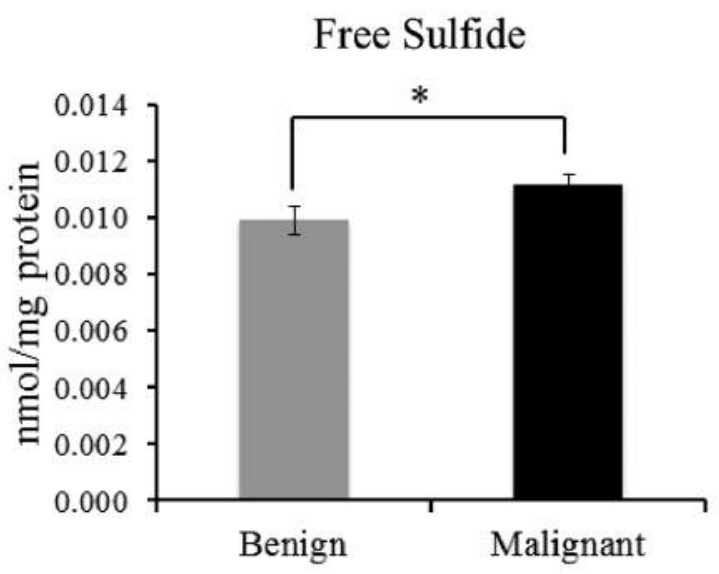

Figure 3. Comparison of the cellular free sulfide $\left(\mathrm{H}_{2} \mathrm{~S}\right)$ pools of benign oral mucosae and OSCC in fifteen patients. Free sulfide $\left(\mathrm{H}_{2} \mathrm{~S}\right)$ is pmol/mg protein. ${ }^{*} p<0.05$.

benign mucosae. MitoNEET was, on average, induced over six-fold in all fourteen OSCC and benign mucosal samples interrogated, higher than any other protein here examined. To our knowledge, this is the first time that mitoNEET has been demonstrated to be increased in OCSS. The reason for this induction in unknown, however higher mitoNEET levels might promote tumor survival via ferroptosis, apoptosis, and autophagy suppression (32).

Next, we looked at TERT and MAPK expression in ten each benign mucosal and OSCC samples. TERT and MARK were induced roughly 2.0- and 2.5-fold, in OSCC compared with the benign mucosal samples, respectively (Figures $2 \mathrm{G}$ and $\mathrm{H}$, and Table III). hTERT is increased in many tumors, including OSCC, where it promotes OSCC progression and the epithelial-mesenchymal transition (37). Similarly, MAPK promotes OSCC progression though multiple pathways, including the induction of cyclin D1 and activation of the PI3K/Akt pathways $(38,39)$.

SQOR protein levels were next examined in ten OSCC and benign mucosal samples. SQOR mediates the first step in $\mathrm{H}_{2} \mathrm{~S}$ mitochondrial metabolism where it catalyzes a twoelectron oxidation of $\mathrm{H}_{2} \mathrm{~S}$ to sulfane sulfur, while using coenzyme $\mathrm{Q}$ as an electron acceptor $(40,41)$. We hypothesized that SQOR protein expression may be increased in OSCC and hence, use $\mathrm{H}_{2} \mathrm{~S}$ as an electron source for the mitochondrial electron transport chain. SQOR however, was not induced in OSCC compared to benign oral mucosae (Figure 2I, Table III). Last, ATM protein levels were examined in eleven patient samples (Figure 2J, Table III). The ATM protein is not induced in OSCC (42). Similar to previous studies, the ATM protein was not induced in
Table III. The average increases in each protein seen when specific protein levels in OCSS were compared to benign oral mucosae. Numbers were rounded off to two decimal places. For all OSCC/benign tissue pairs where the p-value was significant, the protein examined by western blotting was increased in every OSCC/benign tissue pair.

\begin{tabular}{lccc}
\hline Protein & $\begin{array}{c}\text { Average induction } \\
\text { in OSCC/Benign } \\
\text { oral mucosae }\end{array}$ & $\begin{array}{c}\text { Number } \\
\text { of cases } \\
\text { examined }\end{array}$ & $\begin{array}{c}p \text {-Value for } \\
15 \text { pairs } \\
\text { analyzed }\end{array}$ \\
\hline CBS & 2.76 & 15 & Significant \\
CSE & 2.96 & 15 & Significant \\
3-MST & 2.73 & 15 & Significant \\
Nampt & 2.25 & 15 & Significant \\
p-Stat3 & 2.39 & 11 & Significant \\
mitoNEET & 6.76 & 14 & Significant \\
hTERT & 2.92 & 11 & Significant \\
MAPK & 1.81 & 12 & Significant \\
SQOR & 1.04 & 10 & Not Significant \\
ATM & 1.17 & 11 & Not Significant \\
\hline
\end{tabular}

OSCC in our study. Based on this, and our finding that hTERT and MAPK were induced in OSCC as previously found, we conclude that our western blot protocol yielded valid results $(37-39,42)$.

A large body of data indicates that $\mathrm{H}_{2} \mathrm{~S}, \mathrm{CBS}, \mathrm{CSE}$, and 3-MST are increased in many cancer types, where increased $\mathrm{H}_{2} \mathrm{~S}$ and enzyme levels promote tumor growth and invasion, angiogenesis, and metastasis (11-19). Here, all three $\mathrm{H}_{2} \mathrm{~S}-$ synthesizing enzymes were increased in OCSS compared to benign oral mucosae, comparable with previous results for other malignancies (Figure 2A and C (11-16). Additionally, for the first time total cellular free $\mathrm{H}_{2} \mathrm{~S}$ was directly measured in a human tumor. $\mathrm{H}_{2} \mathrm{~S}$ was significantly increased in OSCC compared to benign oral mucase (Figure 3). Interestingly, although the increase in $\mathrm{H}_{2} \mathrm{~S}$ was statistically significant, the increase was modest and less than the 2.7fold increases in the protein expression of CBS, CSE, and 3MST seen here. Similarly, it is also less than the nearly fourfold increase in cellular $\mathrm{H}_{2} \mathrm{~S}$ concentrations seen in buffered bladder tumor homogenates compared to benign bladder tissue homogenates, and in cancer-derived human cell lines compared to counterpart benign tissues $(11,13,15)$. Although our study and many previous studies did not examine $\mathrm{H}_{2} \mathrm{~S}$-synthesizing enzyme activities, the modest increase in OCSS $\mathrm{H}_{2} \mathrm{~S}$ levels seen here suggest that the OSCC is rapidly metabolizing $\mathrm{H}_{2} \mathrm{~S}$, possibly to support malignant cell growth. Support for this comes from previous studies showing that suppression of $\mathrm{H}_{2} \mathrm{~S}$-synthesizing enzyme activities or suppression of their protein expression slows tumor cell growth, while exogenous $\mathrm{H}_{2} \mathrm{~S}$ can increase it $(11-15,18,19)$. 
Our findings here are preliminary and more work needs to be done. For example, OSCC relative CBS, CSE, 3-MST, and SQOR enzymatic activities should be measured. The activities of CBS, CSE, and 3-MST may be increased, increasing $\mathrm{H}_{2} \mathrm{~S}$ synthesis and availability in OSCC, however the work here does not address this. Possible differences in $\mathrm{H}_{2} \mathrm{~S}$ and protein expression between different tumor grades and stages should be examined, which is not possible with the small sample size used herein. Similarly, while SQOR levels were not increased in OSCC, its activity might be increased allowing $\mathrm{H}_{2} \mathrm{~S}$ electrons to be shunted into the mitochondrial electron transport chain to serve as an energy source. Additionally, the $\mathrm{H}_{2} \mathrm{~S}$ cellular half-life in benign oral mucosae and OSCC should be examined, as well as the differences in the specific sulfane species found in benign and malignant tissues. Last, the possible roles of mitoNEET and phospho-Stat 3 ser727 in OSCC as related to $\mathrm{H}_{2} \mathrm{~S}$ and tumor growth should be examined. This work is currently underway in our laboratory.

\section{Conflicts of Interest}

The Authors have no conflicts of interest regarding this work.

\section{Acknowledgements}

The Authors thank the Histology Section of the Tissue Core at the Moffitt Cancer Center and Research Institute for the support in performing the IHC stains. This work was supported in part by HL113303 to C.G.K.

\section{References}

1 Johnson NW, Warnakulasuriya S, Gupta PC, Dimba E, Chindia M, Otoh EC, Sankaranarayanan R, Califano J and Kowalski L: Global oral health inequalities in incidence and outcomes for oral cancer: causes and solutions. Adv Dent Res 23: 237-246, 2011.

2 Warnakulasuriya S: Global epidemiology of oral and oropharyngeal cancer. Oral Oncol 45: 309-316, 2009.

3 Shiboski CH, Shiboski SC and Silverman S Jr.: Trends in oral cancer rates in the United States, 1973-1996. Community Dent Oral Epidemiol 28: 249-256, 2000.

4 Natarajan E and Eisenberg E: Contemporary concepts in the diagnosis of oral cancer and precancer. Dent Clin North Am 55: 63-88, 2011

5 Huber MA and Tantiwongkosi B: Oral and oropharyngeal cancer. Med Clin North Am 98: 1299-1321, 2014.

6 Salahshourifar I, Vincent-Chong VK, Kallarakkal TG and Zain RB: Genomic DNA copy number alterations from precursor oral lesions to oral squamous cell carcinoma. Oral Oncol 50: 404412, 2014

7 Rivera C: Essentials of oral cancer. Int J Clin Exp Pathol 8: 1884-11894, 2015.

8 Ginos MA, Page GP, Michalowicz BS, Patel KJ, Volker SE, Pambuccian SE, Ondrey FG, Adams GL and Gaffney PM: Identification of a gene expression signature associated with recurrent disease in squamous cell carcinoma of the head and neck. Cancer Res 64: 55-63, 2004.
9 Wang R: Physiological implications of hydrogen sulfide: a whiff exploration that blossomed. Physiol Rev 92: 791-896, 2012.

10 Kabil $\mathrm{O}$ and Banerjee R: Redox biochemistry of hydrogen sulfide. J Biol Chem 285: 21903-21907, 2010.

11 Szabo C, Coletta C, Chao C, Módis K, Szczesny B, Papapetropoulos A and Hellmich MR: Tumor-derived hydrogen sulfide, produced by cystathionine- $\beta$-synthase, stimulates bioenergetics, cell proliferation, and angiogenesis in colon cancer. Proc Natl Acad Sci USA 110: 12474-12479, 2013.

12 Bhattacharyya S, Saha S, Giri K, Lanza IR, Nair KS, Jennings NB, Rodriguez-Aguayo C, Lopez-Berestein G, Basal E, Weaver AL, Visscher DW, Cliby W, Sood AK, Bhattacharya R and Mukherjee P: Cystathionine beta-synthase (CBS) contributes to advanced ovarian cancer progression and drug resistance. PLoS One 8: e79167, 2013.

13 Sen S, Kawahara B, Gupta D, Tsai R, Khachatryan M, RoyChowdhuri S, Bose S, Yoon A, Faull K, Farias-Eisner R and Chaudhuri G: Role of cystathionine $\beta$-synthase in human breast Cancer. Free Radic Biol Med 86: 228-238, 2015.

14 Patel S, Ansari J, Meram A, Abdulsattar J, Cotelingam J, Coppola D, Ghali G and Shackelford R: Increased nicotinamide phosphoribosyltransferase and Cystathionine-Beta-Synthase in oral cavity squamous cell carcinomas. Int J Clin Exp Pathol 10: 702-707, 2017.

15 Gai JW, Qin W, Liu M, Wang HF, Zhang M, Li M, Zhou WH, Ma QT, Liu GM, Song WH, Jin J and Ma HS: Expression profile of hydrogen sulfide and its synthases correlates with tumor stage and grade in urothelial cell carcinoma of bladder. Urol Oncol 34: 166.e15-20, 2016.

16 Jurkowska H, Placha W, Nagahara $\mathrm{N}$ and Wrobel M: The expression and activity of cystathionine- $\gamma$-lyase and 3mercaptopyruvate sulfurtransferase in human neoplastic cell lines. Amino Acids 41: 151e158, 2011.

17 Vitvitsky V, Kabil O and Banerjee R: High turnover rates for hydrogen sulfide allow for rapid regulation of its tissue concentrations. Antioxid Redox Signal 17: 22-31, 2012.

18 Zhang S, Bian H, Li X, Wu H, Bi Q, Yan Y and Wang Y: Hydrogen sulfide promotes cell proliferation of oral cancer through activation of the COX2/AKT/ERK1/2 axis. Oncol Rep 35: 2825-2832, 2016.

19 Ma Z, Bi Q and Wang Y: Hydrogen sulfide accelerates cell cycle progression in oral squamous cell carcinoma cell lines. Oral Dis 21: 156-162, 2015

20 Leskova A, Pardue S, Glawe JD, Kevil CG and Shen X: Role of thiosulfate in hydrogen sulfide-dependent redox signaling in endothelial cells. Am J Physiol Heart Circ Physiol 313: H256-H264, 2017.

21 Shen X, Peter EA, Bir S, Wang R and Kevil CG: Analytical measurement of discrete hydrogen sulfide pools in biological specimens. Free Radic Biol Med 15: 2276-2283, 2012.

22 Joos $\mathrm{T}$ and Bachmann J: Protein microarrays: potentials and limitations. Front Biosci 14: 4376-4385, 2009.

23 Sanokawa-Akakura R, Ostrakhovitch EA, Akakura S, Goodwin $\mathrm{S}$ and Tabibzadeh S: $\mathrm{A}_{2} \mathrm{~S}$-Nampt dependent energetic circuit is critical to survival and cytoprotection from damage in cancer cells. PLoS One 23: e108537, 2014.

24 Shackelford RE, Mayhall K, Maxwell NM, Kandil E and Coppola D: Nicotinamide phosphoribosyltransferase in malignancy: a review. Genes Cancer 4: 447-456, 2013. 
25 Zhang X, Wu X, Zhang F, Mo S, Lu Y, Wei W, Chen X, Lan L, Lu B and Liu Y: Paclitaxel induces apoptosis of esophageal squamous cell carcinoma cells by downregulating STAT3 phosphorylation at Ser727. Oncol Rep 37: 2237-2244, 2017.

26 Plaza-Menacho I, van der Sluis T, Hollema H, Gimm O, Buys $\mathrm{CH}$, Magee $\mathrm{AI}$, Isacke CM, Hofstra RM and Eggen BJ: Ras/ERK1/2-mediated STAT3 Ser727 phosphorylation by familial medullary thyroid carcinoma-associated RET mutants induces full activation of STAT3 and is required for c-fos promoter activation, cell mitogenicity, and transformation. J Biol Chem 282: 6415-6424, 2007.

27 Wakahara R, Kunimoto H, Tanino K, Kojima H, Inoue A, Shintaku $\mathrm{H}$ and Nakajima K: Phospho-Ser727 of STAT3 regulates STAT3 activity by enhancing dephosphorylation of phospho-Tyr705 largely through TC45. Genes Cells 17: 132-145, 2012.

28 Yang SF, Yuan SS, Yeh YT, Wu MT, Su JH, Hung SC and Chai CY: The role of p-STAT3 (ser727) revealed by its association with Ki-67 in cervical intraepithelial neoplasia. Gynecol Oncol 98: 446-452, 2005.

29 Calvert JW, Jha S, Gundewar S, Elrod JW, Ramachandran A, Pattillo CB, Kevil CG and Lefer DJ: Hydrogen sulfide mediates cardioprotection through Nrf2 signaling. Circ Res 105: 365-374, 2009.

30 Deepak Roshan VG, Sinto MS, Thomas S and Kannan S: Cyclin D1 overexpression associated with activation of STAT3 in oral carcinoma patients from South India. J Cancer Res Ther 14: 403408, 2018.

31 You J, Shi X, Liang H, Ye J, Wang L, Han H, Fang H, Kang W and Wang T: Cystathionine- $\gamma$-lyase promotes process of breast cancer in association with STAT3 signaling pathway. Oncotarget 8: 65677-65686, 2017.

32 Sohn YS, Tamir S, Song L, Michaeli D, Matouk I, Conlan AR, Harir Y, Holt SH, Shulaev V, Paddock ML, Hochberg A, Cabanchick IZ, Onuchic JN, Jennings PA, Nechushtai R and Mittler R: NAF-1 and mitoNEET are central to human breast cancer proliferation by maintaining mitochondrial homeostasis and promoting tumor growth. Proc Natl Acad Sci USA 110: 14676-14681, 2013.

33 Mittler R, Darash-Yahana M, Sohn YS, Bai F, Song L, Cabantchik IZ, Jennings PA, Onuchic JN and Nechushtai R: NEET proteins: A new link between iron metabolism, reactive oxygen species, and cancer. Antioxid Redox Signal, 2018. 10.1089/ars.2018.7502. [Epub ahead of print]
34 Landry AP, Cheng Z and Ding H: Reduction of mitochondrial protein mitoNEET [2Fe-2S] clusters by human glutathione reductase. Free Radic Biol Med 81: 19-127, 2015.

35 Rawal RM, Patel DD, Patel BP, Patel MM, Wadhwa MK, Patel PS and Bhatavdekar JM: Assessment of glutathione-S-transferase and glutathione reductase in patients with squamous-cell carcinoma of buccal mucosa. Int J Cancer 83: 727-731, 1999.

36 Chhabra A, Mishra S, Kumar G, Gupta A, Keshri GK, Bharti B, Meena RN, Prabhakar AK, Singh DK, Bhargava K and Sharma M: Glucose-6-phosphate dehydrogenase is critical for suppression of cardiac hypertrophy by $\mathrm{H}_{2} \mathrm{~S}$. Cell Death Discov 4: 6, 2018.

37 Zhao T, Hu F, Qiao B, Chen Z and Tao Q: Telomerase reverse transcriptase potentially promotes the progression of oral squamous cell carcinoma through induction of epithelialmesenchymal transition. Int J Oncol 46: 2205-2215, 2015.

38 Fu X and Feng Y: QKI-5 suppresses cyclin D1 expression and proliferation of oral squamous cell carcinoma cells via MAPK signalling pathway. Int J Oral Maxillofac Surg 44: 562-567, 2015.

39 Murugan AK, Munirajan AK and Tsuchida N: Ras oncogenes in oral cancer: the past 20 years. Oral Oncol 48: 383-392, 2012.

40 Jackson MR, Melideo SL and Jorns MS: Human sulfide:quinone oxidoreductase catalyzes the first step in hydrogen sulfide metabolism and produces a sulfane sulfur metabolite. Biochemistry 51: 6804-6815, 2012.

41 Jackson MR, Melideo SL and Jorns MS: Role of human sulfide: quinone oxidoreductase in $\mathrm{H}_{2} \mathrm{~S}$ metabolism. Methods Enzymol 554: 255-270, 2015.

$42 \mathrm{He} \mathrm{Y,} \mathrm{Chen} \mathrm{Q} \mathrm{and} \mathrm{Li} \mathrm{B:} \mathrm{ATM} \mathrm{in} \mathrm{oral} \mathrm{carcinogenesis:} \mathrm{association}$ with clinicopathological features. J Cancer Res Clin Oncol 134: 1013-1020, 2008. 